Relations industrielles

Industrial Relations

\title{
Notre troisième Congrès
}

\section{La Direction}

Volume 3, numéro 6, février 1948

URI : https://id.erudit.org/iderudit/1023596ar

DOI : https://doi.org/10.7202/1023596ar

Aller au sommaire du numéro

Éditeur(s)

Département des relations industrielles de l'Université Laval

ISSN

0034-379X (imprimé)

1703-8138 (numérique)

Découvrir la revue

Citer ce document

La Direction (1948). Notre troisième Congrès. Relations industrielles / Industrial Relations, 3(6), 81-81. https://doi.org/10.7202/1023596ar

Tous droits réservés @ C Département des relations industrielles de l’Université Laval, 1948
Ce document est protégé par la loi sur le droit d'auteur. L’utilisation des services d'Érudit (y compris la reproduction) est assujettie à sa politique d'utilisation que vous pouvez consulter en ligne.

https://apropos.erudit.org/fr/usagers/politique-dutilisation/ 
publié par le Département des relations industrielles de la Faculté des sciences sociales de Laval, Québec

\section{NOTRE TROISIÈME CONGRÈS}

Le troisième Congrès du Département des relations industrielles aura lieu les 19 et 20 avril prochain. Il se déroulera comme par le passé dans les salles du Château Frontenac où la distinction reposante s'allie au charme de l'accueil. Ce Congrès sera un succès grâce à la collaboration de tous ceux qui ont déjà participé aux précédents. Il sera un succès car il répond à un besoin social. Economistes, sociologues, chefs du syndicalisme patronal ou ouvrier, directeurs de personnel, fonctionnaires du travail y trouveront un moyen d'expression, une occasion de méditer sur les problèmes qui les préoccupent et de renouer de précieuses relations.

Le Congrès des Relations industrielles de Laval complète et prolonge pour employeurs et salariés les assises annuelles de leurs organisations respectives. Le caractère pratique, marqué par et pour l'action des congrès syndicaux ne leur permet pas d'utiliser la formule de la conférence si bien appropriée à un congrès universitaire. Félicitons-nous que les hommes d'action trouvent le temps d'être aussi des hommes d'étude. Le peuple y gagnera d'être plus sagement dirigé.

Nous avons donné un thème au Congrès: * Formes de collaboration patronale-ouvrière. \ Le titre peut paraitre prétentieux tant il est vaste et compréhensif. Nous ne toucherons cependant quà quelques formes de collaboration, celles qui nous ont semblé les plus pressantes et les plus susceptibles d'améliorer la condition des hommes dans les temps présents.

Nous étudierons donc cette collaboration à l'échelle de l'entreprise et de l'industrie : $1^{0}$ sur le plan de la convention collective (conférencier: M. Philippe Lessard, président de la Fédération Nationale des Travailleurs de la Pulpe et du Papier, Inc.); $2^{\circ}$ sur celui des comités d'entreprise (confériencier: M. Raymond Gérin, L.Sc.S., secrétaire de la Régionale de Québec de l'Association professionnelle des Industriels); $3^{\circ}$ sur celui de la formation professionnelle (conférencier: M. Gabriel Rousseau, conseiller technique à l'Apprentissage au ministère du Travail); $4^{0}$ enfin, sur le plan de la sécurité du travail, de la médecine et de lhygiène industrielles (conférencier: Dr Wilfrid Leblond, professeur d'hygiène industrielle à la Faculté des sciences sociales).

Chaque conférence et la discussion qui suivra prendront une séance complète. Nous n'avons pas voulu surcharger le programme afin de donner aux congressistes l'opportunité d'échanger leurs vues.

$\mathrm{Si}$ la collaboration patronale-ouvrière n'est pas une idée nouvelle, elle n'en garde pas moins toute son actualité. Un sujet comme la convention collective paraît vieux style mais si l'on met en présence certaines oppositions entre la Loi des Relations ouvrières et la Loi de la Convention collective, il devient passionnant. Les comités d'entreprise ont connu au pays une certaine popularité durant la guerre alors qu'il s'agissait d'accroîttre la production. Pourquoi ces comités, excellents en temps de guerre, sont-ils mis en veilleuse en temps de paix? N'y a-t-il pas là lopportunité tant attendue de développer cette communauté de travail dont on rêve sans la réaliser? Des initiatives heureuses ont été provoquées par la mise en vigueur de la Loi d'Aide à l'Apprentissage; il vaut qu'elles soient connues et que le patronat, le travail et l'Etat préparent en commun des formules nouvelles de coopération dans ce domaine. Enfin l'homme doit être protégé dans sa santé, son capital le plus précieux. Nous avons de graves carences de ce côté. Il y a là beaucoup à améliorer, encore plus à créer.

La clóture du Congrès sera marquée par un dîner-conférence sous la présidence d'honneur de l'honorable Antonio Barrette, ministre du Travail. Le Très Révérend Père G.-H. Lévesque, doyen de la Faculté des sciences sociales, a bien voulu accepter notre invitation pressante d'être le conférencier. Le sujet qu'il traitera ? . . Il faudra venir le connaître, mardi soir, le 20 avril.

Nous prisons nos lecteurs de hâter leur inscription. Nous avions, l'an passé, au delà de trois cents congressistes. Il y en aura davantage cette année ! Qu'on se presse afin de faciliter le travail de préparation de ces grandes assises. N'avons-nous pas le droit d'exiger une prompte collaboration qu'inspire éloquemment le thème du Congres ? 